\title{
LA CRISIS DEL HUMANISMO EN FOUCAULT Y HABERMAS ${ }^{1}$
}

\author{
DAVID A. ROLDÁN \\ Instituto Universitario ISEDET \\ (Buenos Aires)
}

\begin{abstract}
RESUMEN: El objeto de este artículo es la crítica al humanismo, tal como ha sido desarrollada Michel Foucault y Jürgen Habermas. En primer término, el autor expone la sustancia de la crítica foucaultiana al humanismo (como parte de la episteme moderna, bajo los influjos de una tesis «metafísica» del sujeto). En segundo término, el autor presenta el proyecto de Habermas, quien también estuvo atento a la crisis del humanismo y la antropología filosófica, e intervino en estos debates, en la década de 1980, oponiéndose al post-estructuralismo, mediante el señalamiento del déficit normativo de su crítica a la modernidad, el humanismo y la filosofía del sujeto. El objetivo es, en primer lugar, plantear correctamente las críticas de Foucault y Habermas al humanismo, atendiendo mínimamente al contexto en que tuvieron lugar. En segundo término, el autor busca identificar la tesis que divide al proyecto foucaultiano del proyecto habermasiano, para, en tercer lugar, proceder a una evaluación crítica de ambos proyectos en relación al lugar que deben ocupar las luchas sociales emancipatorias tras la bancarrota del humanismo.
\end{abstract}

PALABRAS CLAVE: Modernidad, humanismo, filosofía del sujeto, poder

\section{The crisis of humanism in Foucault and Habermas}

ABSTRACT: The purpose of this paper is the criticism of humanism, in the way that has been developed by Michel Foucault and Jürgen Habermas. In first place, the author presents the substance of the criticism of Foucault to humanism (as a part of the modern episteme, under the influences of a «metaphysical» thesis of the subject). In second place, the author presents the draft of Habermas, who was also aware of the crisis of humanism and philosophical anthropology, and intervened in these debates, in the 1980s, with his opposition to post-structuralism, by pointing the normative deficit of his critique to Modernity. The general aim is, first, to properly raise criticisms of Foucault and Habermas to humanism, attending the context in which they occurred. Secondly, the author seeks to identify the thesis that divides the Habermasian project from the Foucaultian project. Finally, the author makes a critical assessment of both projects in relation to the place that emancipatory social struggles should occupy after the collapse of humanism.

KEY WORDS: Modernity, humanism, philosophy of the subject, power.

\section{La SUSTANCIA DE La CRÍtiCa FOUCAUlTiana AL HUMANismo}

En Foucault la crítica al humanismo opera en conjunto con la crítica a la episteme moderna, la crítica a la filosofía del sujeto, la metafísica y, posteriormente, al «autor». Habiéndose adherido en algunos de sus primeros textos de la década de 1950 a cierta «fenomenología», el Foucault de la década de 1960

1 El presente artículo fue escrito en noviembre de 2012. Quiero agradecer a Alcira Bonilla, Mario Gómez y Claudio Cormick por sus aportes durante la elaboración de este trabajo. 
ya está inscrito en un proyecto de ruptura con dicha escuela filosófica. En la Historia de la locura en la época clásica, de 1961, Foucault «reemplazaba» como marco teórico la fenomenología por un tipo de crítica de la cultura que encontraba su inspiración en El origen de la tragedia, de Nietzsche. Al contrario de sus obras posteriores, aquí Foucault no tenía una explícita intención política, sino que buscaba medir el mayor grado de vitalidad y creatividad de un proceso cultural, sobre una «base antirracionalista», como ha señalado Stéphane Háber². Si la obra genial cuenta, en su contexto de producción, con una zona fronteriza con la locura, el proceso de confinamiento del «loco» en el asilo exhibe la tendencia a reducir las posibilidades de una transformación del orden vigente.

Con la adopción de cierto estructuralismo, Foucault elaboró en 1966 una crítica de las ciencias humanas en tanto que dependientes de un «fundamento» que se ha vuelto problemático. Ese fundamento, común a todas las ciencias humanas del siglo XIX, es denominado por Foucault episteme, y constituye el «objeto de estudio» de Las palabras y las cosas ${ }^{3}$. Para Foucault, los cambios superficiales de la historia, las epopeyas de liberación de un pueblo, o los proyectos revolucionarios de una clase, constituyen fenómenos que descansan sobre supuestos que aún no han sido explicitados. Esos supuestos pueden denominarse episteme, y juegan un rol epistemológico y ontológico a la vez, aunque no son «eternas e intemporales», sino que se suceden una a otra en lo que llamamos «historia». Por lo tanto, el interés primordial de Foucault ahora es estudiar la discontinuidad entre epistemes: de la episteme clásica a la moderna, y de la moderna a la «contemporánea» (a falta de un nombre explícito).

Foucault abre Las palabras y las cosas con la famosa referencia al cuento de Borges, que le permitió orientar la mirada hacia esa «zona intermedia» entre lo empírico y el saber científico, entre las cosas y las palabras. Ese «entre» será denominado episteme, un "orden», que es el gran supuesto de una época. Si es relevante caracterizar cada episteme, más aún lo es describir sus discontinuidades.

Foucault divide lo que llamamos «modernidad» en tres períodos. El período clásico, que va de Descartes a Kant; el período «moderno», que va desde Kant como «umbral», hasta Husserl, y lo que sería un período «contemporáneo» (sin asignarle un nombre explícito). Nos centraremos en las dos discontinuidades clave: de la época clásica a la moderna, y de la moderna a la «contemporánea» (1960). La época clásica es la época de la «representación», en donde se supone que el lenguaje representa la realidad. Lo infinito aparece representado, incluido, en la finitud del hombre, la cual todavía no aparece representada como tal.

2 HABER, S., «Foucault y Habermas: dos comienzos filosóficos contemporáneos», en $\mathrm{Ha}$ bermas / Foucault. Trayectorias cruzadas, confrontaciones críticas, ed. Ives Cusset y Stéphane Haber, trad. Heber Cardoso (Buenos Aires: Nueva Visión, 2007), 40. En cuanto a la vitalidad de los procesos culturales, podría verse una influencia de Friedrich Nietzsche, Sobre la utilidad y el perjuicio de la historia para la vida [II intempestiva], trad. Germán Cano (Madrid: Biblioteca Nueva, 1999).

3 Foucault, M., Les Mots et les Choses (Paris: Gallimard, 1966). 
Pensemos en el rol clave de «la idea de lo infinito» en Descartes ${ }^{4}$, o en el lugar del rey en el cuadro de Velázquez Las meninas, que acompaña toda la reflexión de Foucault en esta obra. El rey sostenía la representación, era el punto al cual tendía la representación y el que garantizaba su unidad. El lugar del rey es el lugar del sujeto, de un Cogito transparente a sí mismo, un Cogito que todavía no está «quebrado», para usar la expresión de Ricoeur ${ }^{5}$. Un sujeto que no es finito, en el sentido de que la «idea de lo infinito», puesta en él, no acarrea el problema de la finitud. Las tres positividades: vida, trabajo y lenguaje, eran abordadas como «historia natural», "análisis de la riqueza», y reflexión gramatical sobre el lenguaje. Para la época clásica, «el hombre no existe». Lo que entendemos por «hombre», su finitud, aparece con otro abordaje, propio de la «episteme moderna», que abandona el primado de la representación (con su entrecruzamiento con las palabras), y que Foucault adosa a la biología de Cuvier, la economía de David Ricardo y el surgimiento de los primeros filólogos. En el caso del lenguaje, éste habría retrasado aún más su «ingreso» al centro de la reflexión si no fuera por la importancia que le dio Nietzsche ${ }^{6}$.

Una vez descritas las epistemes clásica y moderna, Foucault se ocupa de mostrar las aporías a las que condujo la reflexión cuyo centro era el hombre: la repetición de lo empírico en lo trascendental (o su «duplicación», aquí vemos cómo Kant es una «bisagra»), la constante lucha de la conciencia, del Cogito, por "pensar lo impensado», y el siempre frustrante intento de «retorno al origen». Es notable (y habrá sido muy irritante para sus contemporáneos) el modo en que Foucault logra argumentar que el propio Husserl queda supeditado a las aporías de la episteme moderna. De este modo, Foucault envía un claro mensaje a sus contemporáneos fenomenólogos: debemos intentar salir de esta filosofía moderna de la finitud, es una episteme o un paradigma «agotado».

Y al decir esto, Foucault también está enviando un mensaje al marxismo: esta es una filosofía que descansa también sobre una episteme agotada. Si había problemas con que "el existencialismo sea un humanismo» ${ }^{7}$, también lo habrá con que el marxismo sea un humanismo, como mostrará el propio Althusser en ese mismo contexto ${ }^{8}$. Al advertir las estructuras universales en las cuales tiene lugar la existencia humana, que otrora se creía "consciente», "principio de acción», «autónoma», aquellas aparecen ahora como «disueltas» en dichas estructuras. Lo que hemos llamado «hombre», eso mismo, se disuelve. En 1967 Foucault fue entrevistado por Paolo Caruso, quien se mostró incisivo en la cuestión del humanismo. Allí Foucault considera el humanismo como «tecnocracia»:

4 Descartes, R., «Meditaciones metafísicas», en Obras escogidas, trad. Ezequiel de Olaso y Tomas Zwanck, 2.a ed. (Buenos Aires: Charcas, 1980). Ver Tercera Meditación.

5 Ricoevr, P., Soi-même comme un autre (Paris: Seuil, 1990), prologue.

6 Foucault, M., Las palabras y las cosas. Una arqueología de las ciencias humanas, trad. Elsa Cecilia Frost, 17.a ed. (México: Siglo xxi, 1986), 297.

7 SARTRE J-P., L'existencialisme est un humanisme (Paris: Nagel, 1946).

8 Althusser, L., Pour Marx (Paris: François Maspero, 1965). 
Yo no quisiera que me considerara el propugnador de un humanismo tecnocrático, o de una especie de humanismo que no se atreve a proclamarse como tal. Nadie es tan humanista como los tecnócratas. Por otra parte, ha de ser posible hacer una política de izquierdas que no utilice todos esos confusos mitos humanistas. Creo que el óptimum del funcionamiento social se puede definir como una determinada relación entre incremento demográfico, consumo, libertad individual, posibilidad para todos de gozar, sin apoyarse nunca en la idea de hombre; un óptimum de funcionamiento se puede definir de una manera intrínseca, sin que sea preciso decir "para quién» es mejor que una cosa sea así. En cambio, los tecnócratas son humanistas y la tecnocracia es una forma de humanismo. En realidad, los tecnócratas se creen con derecho a ser los únicos para definir lo que es la «felicidad de los hombres» y para intentar alcanzarla? .

Como puede apreciarse con claridad, Foucault rechaza el humanismo por tratarse de una hipótesis que justifica cierto tipo de dominación, de planificación de la «razón occidental» sobre la existencia humana (incluso se observan aquí ciertas preocupaciones que luego serán explicitadas, en la década siguiente, en sus análisis de la población y el neoliberalismo $)^{10}$. En otra oportunidad, Foucault insiste con identificar al humanismo como la síntesis de las «explicaciones» que nos impiden «tomar el poder»:

Entiendo por humanismo el conjunto de discursos a través de los cuales se le ha dicho al hombre occidental: aunque no ejerzas el poder, puedes no obstante ser soberano. Mejor aún: cuanto más renuncies a ejercer el poder y más te sometas al que te impongan, más soberano serás. El humanismo es quien ha inventado sucesivamente todas estas soberanías sometidas, tales como el alma (soberanía del cuerpo, sometida a Dios), la conciencia (soberanía del orden de los juicios, sometida al orden de la verdad), la libertad fundamental (soberanía interiormente, pero que consiente y está de acuerdo con su destino exteriormente), el individuo (soberano titular de derechos, sometido a las leyes o a las reglas de la sociedad). En resumen, el humanismo es todo aquello con lo que, en Occidente, se ha suprimido el deseo de poder, se ha prohibido querer el poder y se ha excluido la posibilidad de tomarlo ${ }^{11}$.

Pero si la tecnocracia y la modernidad occidental pueden ser acusadas de dominarnos con la misma idea de «hombre» y "humanismo», en el caso del marxismo esta objeción podría quedar indemne, toda vez que su finalidad consiste en suprimir la dominación clasista. Sin embargo, ya en 1966 Foucault había denunciado al marxismo como fundado en la episteme moderna, al concebir la conciencia y la autoconciencia de clase bajo el supuesto de una «total

9 CARuso, P., Conversaciones con Lévi-Strauss, Foucault y Lacan, trad. F. Serra Cantarell (Barcelona: Anagrama, 1969).

10 Foucault, M., El nacimiento de la biopolítica. Curso en el Collège de France (1978-1979), trad. Horacio Pons (Buenos Aires: Fondo de Cultura Económica, 2007).

11 Foucault, M., Microfísica del poder, trad. Julia Varela y Fernando Álvarez-Uría, 2.a ed. (Madrid: Las ediciones de la Piqueta, 1979), 34. 
transparencia» del sujeto para-sí, reeditando así a las filosofías del Cogito, que se rigen con el imperativo de "pensar lo impensado», cuando esto no es más que una ilusión moderna: convertir en «Lo Mismo», lo otro del hombre. Decía Foucault:

Dado que en suma no era más que un insistente doble, jamás había sido reflexionado por sí mismo de modo autónomo; de aquello de lo que era lo Otro y la sobra recibió la forma complementaria y el nombre invertido: fue el An sich frente al Für sich, de la fenomenología hegeliana; fue el Unbewusstes para Schopenhauer; fue el hombre enajenado para Marx ${ }^{12}$.

Del mismo modo, Marx es criticado en la segunda figura que emplea Foucault: la obsesión moderna por el «retorno a los orígenes»:

Por ello el pensamiento moderno está consagrado, de un cabo a otro, a la gran preocupación del retorno, al cuidado de recomenzar, a esta extraña inquietud que lo hace sentirse obligado a repetir la repetición. Así, desde Hegel a Marx y a Spengler se ha desplegado el tema de un pensamiento que, por el movimiento en que se realiza — totalidad reunida, reaprehensión violenta en el extremo del desenlace, ocaso solar - se curva sobre sí mismo, ilumina su propia plenitud, cierra su círculo, se reencuentra en todas las figuras extrañas de su odisea y acepta desaparecer en este mismo océano del que había surgido $[\ldots]^{13}$.

El problema aquí es, en el fondo, similar. El retorno al origen que pregona Marx implica una esencia de hombre, una identidad, que será reencontrada en un retorno a los orígenes, así como la búsqueda de hacer consciente lo inconsciente deseaba dar con esa identidad del hombre tras la enajenación. El humanismo implica, como filosofía del sujeto, una cierta esencia humana que está todavía por realizarse de manera autónoma. Si bien no toda filosofía del sujeto implica esencialismo, lo que une a ambas filosofías es el supuesto de que la reconciliación se logrará por una acción humana (individual en el «peor» de los casos existencialistas, y colectiva en el marxismo). Hay una «esperanza» que se cifra sobre la acción humana, la acción del sujeto, la realización del ideal humano, etc. No es de sorprender que haya implicada aquí una filosofía de la historia, en términos de realización de la humanidad o reconciliación como «sentido» al que tiende, o debería tender, la historia. Y esta ruptura no se circunscribe a Las palabras y las cosas, sino que en 1971 Foucault sigue profundizando, desde Nietzsche, su crítica al hegelianismo y al marxismo o, peor aún, al marxismo hegeliano ${ }^{14}$.

12 Foucault, Las palabras y las cosas, 318.

13 Ibíd., 324-325.

14 Foucault, M., «Nietzsche, la généalogie, l'histoire», en Hommage à Jean Hyppolite (Paris: PUF, 1971), 145-172; Foucault, M., Nietzsche, la genealogía, la historia, trad. José Vázquez Pérez (Valencia: Pre-textos, 2004). 


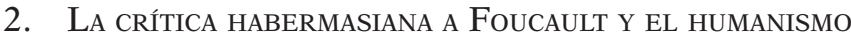

En la década del '50 y ‘60 Habermas ya había realizado algunas críticas a Gehlen y Plessner, en razón del carácter conservador y reaccionario que esas antropologías filosóficas representaban para su generación ${ }^{15}$. El año 1968 fue clave para el espectro intelectual francés y para la filosofía social de origen alemán. Si el existencialismo y el marxismo representaban distintas teorías que se ponían en juego en el mayo francés, no es de extrañar que hayan sido esas teorías las que sintieron con más profundidad la crisis posterior. Si en el ámbito francés todo giraba en torno a Sartre, con su peculiar síntesis de existencialismo y marxismo ${ }^{16}$, en la filosofía social alemana podría decirse que a Marcuse le cupo un rol análogo. Es por ello que en una famosa entrevista que Habermas realiza a Marcuse, en 1977, se ponen en juego los supuestos con los que la nueva generación quiere romper ${ }^{17}$. Por cierto, Habermas, en aquella entrevista, es particularmente insistente con los supuestos de una «antropología filosófica» que detecta en Marcuse ${ }^{18}$. Se trata de las referencias a cierta «fuerza libidinal» con la que Marcuse dota de una base biológica a su proyecto filosófico. Para 1977, Habermas ya había presentado su crítica a la epistemología, con el despliegue y el reconocimiento de «intereses» previos al conocimiento, y que dotaban a las ciencias sociales críticas de una peculiar síntesis entre el Verstehen de las Geisteswissenschaften y el proyecto emancipatorio del marxismo. Sometiéndolo a una brutal simplificación, puede decirse que desde 1968 hasta 1981, lo que sucede en el propio desarrollo de Habermas consiste en pasar de aquellas consideraciones epistemológicas a una posible reconstrucción del materialismo histórico, que se basaba en la incorporación de los estadios evolutivos de Piaget y las consideraciones cognitivas de Kohlberg ${ }^{19}$. Con esto, Habermas intentaba salir de cierto paradigma teleológico-productivista (de un modo ya diverso, en relación a la primera generación de la Escuela de Frankfurt), y había comenzado a dar

15 Habermas, J., Philosophisch-politische Profile (Frankfurt am Main: Suhrkamp Verlag [orig. 1981], 1984) (los caps. 4 y 5 están dedicados a Gehlen y Plessner, respectivamente).

16 SARTRE, J-P., Critique de la raison dialectique (précédé de Question de méthode). Tome I Théorie des ensembles pratiques (Paris: Gallimard, 1960).

17 El tema de la revolución en Marcuse es objeto de análisis específico en otro texto, que tiene varias versiones en castellano, ver Jürgen Habermas, «Termidor psíquico y renacimiento de la subjetividad rebelde (1980)», en Perfiles filosófico-políticos, trad. Manuel Jiménez Redondo (Madrid: Taurus, 1975), 283-296; Habermas, J., «La psique "al termidor" y el renacimiento de la subjetividad rebelde», en Habermas y la modernidad, trad. Francisco Rodríguez Martín (Madrid: Cátedra, 1988), 111-126.

18 Habermas, J., «Diálogo con Herbert Marcuse (1977)», en Perfiles filosófico-políticos, trad. Manuel Jiménez Redondo (Madrid: Taurus, 1975), 250.

19 Habermas, J., La reconstrucción del materialismo histórico, trad. Jaime Nicolás Muñiz y Ramón García Cotarelo (Madrid: Taurus [orig. 1976], 1981). 
los primeros pasos, siguiendo a Apel ${ }^{20}$, en cuanto a la incorporación del giro lingüístico en la epistemología, la ética y la filosofía social crítica. Es así que llegamos, en 1981, a la Teoría de la acción comunicativa, en la cual el filósofo de Frankfurt realiza varios movimientos. Por un lado, depone el paradigma "productivista», y la consecuente prioridad de las relaciones de intercambio de bienes materiales (según la cosmovisión marxista), hacia una dimensión presuntamente más fundamental, que serían los intercambios simbólicos, entre los cuales el lenguaje y, más específicamente, los actos de habla, ocuparían un lugar privilegiado. Huelga decir que esto es una crítica a la antropología de Marx. Por otra parte, la clásica teoría de la cosificación de la consciencia (que de la primera generación de la Escuela llegaba a Marx, pasando por Lucáks ${ }^{21}$ ), era ahora reemplazada por el dualismo entre sistema y Lebenswelt, (la "colonización de la Lebenswelt» por parte de los imperativos de sistema). Una vez realizado esto, cuatro años más tarde, Habermas critica a Foucault en el Diskurs der Moderne, del que nos ocuparemos ahora ${ }^{22}$.

Si Bergson, Dilthey y Simmel tenían como concepto trascendental básico la «vida» (presente hasta Heidegger en cierto modo), Foucault y Derrida pretendieron continuar la crítica nietzscheana en términos de "crítica de la metafísica». Derrida confluyó en una «crítica a la metafísica de la presencia», y Foucault, por su parte, elevó el poder como referencial transcendental básico, arribando a una sola tesis: lo único que perdura es el poder ${ }^{23}$.

Si Heidegger habló de una "historia del ser» y de un carácter epocal, Foucault hará lo propio con una «anticiencia» que desenmascare el carácter opresivo de las ciencias humanas, en tanto que prácticas discursivas que se fundan en un «a priori histórico» que se expresa con la «aparición» del «hombre» en el siglo XIX.

Según Habermas, Foucault advirtió rápidamente que no podía seguir a Heidegger, porque éste había quedado atrapado en la misma ilusión del retorno a un origen arcaico (¿al igual que toda la hermenéutica?). Entonces, Lévi-Strauss y Lacan quedaron como los únicos que se despertaron del sueño antropológico y su esfuerzo por retornar al origen; fueron capaces de pensar (en) «el vacío del hombre desaparecido» ${ }^{24}$.

20 Cf. Apel, K-O., «Narración autobiográfica del proceso filosófico recorrido con Habermas», en Debates en torno a la ética del discurso de Apel. Diálogo filosófico Norte-Sur desde América Latina, ed. Enrique Dussel (México: Siglo xxi, 1994), 192-206.

${ }_{21}$ LukÁcs, G., Geschichte und Klassenbewußtsein. Studien über marxistische Dialektik (Berlin: Der Malik Verlag, 1923).

22 Habermas, J., Der philosophische Diskurs der Moderne (Frankfurt am Main: Suhrkamp Verlag, 1985).

23 Habermas, J., El discurso filosófico de la modernidad, trad. Manuel Jiménez Redondo (Buenos Aires: Katz Editores [orig. 1985], 2008), 276.

24 Ibíd., 292. 
Siguiendo a Dreyfus y Rabinow ${ }^{25}$, podemos afirmar que Habermas muestra las limitaciones concomitantes al proyecto de la Arqueología del saber (1969), en donde Foucault otorga una primacía tal al ámbito discursivo que es éste mismo el que terminaría regulando sus propias aplicaciones (en otras palabras, significaría suponer que una norma puede regular ella misma su contexto de aplicación o su funcionamiento efectivo). El poder operaría en un nivel discursivo tan amplio que llegaría, capilarmente, a constituir cada aspecto de lo que llamamos «realidad». Esto se logra, dice Habermas, con dos nivelaciones: por un lado, se nivela toda voluntad de saber con la voluntad de poder (tesis que remite a Nietzsche, en definitiva). Así, ya no habría diferencia entre la relación sujeto-objeto de las ciencias naturales y las Geisteswissenschaften (consecuentemente, también se nivelarían las «ciencias sociales críticas», de las que hablaba Habermas en $1968^{26}$ ). La otra nivelación está en la concepción misma del «poder» que tiene Foucault, quien sería peculiarmente ambiguo, tanto para servirse de esa categoría como un instrumento heurístico (para Habermas, Foucault puede ser considerado un sociólogo funcionalista que realiza «sociología del saber» con orientación histórica), como para dotar a su proyecto de los tintes de una genealogía desenmascaradora de la razón occidental ${ }^{27}$. Así, Habermas sostiene que, en este segundo aspecto, para Foucault el «poder» es utilizado para elaborar una "teoría de la constitución trascendental de la experiencia» ${ }^{28}$, algo que, por otra parte, constituye una de las posibles interpretaciones de los «intereses» de los que hablaba Habermas en $1968^{29}$. Borrando esta operación de nivelación, Foucault ofrece en la década de 1970 (siempre para Habermas), una actitud positivista que tiene, a su vez, pretensiones críticas. Y es allí a dónde conduce todo el análisis y el «ataque» de Habermas a Foucault: el déficit normativo para elaborar una crítica como la que se entiende que está realizando el filósofo francés.

El déficit normativo se deja ver en algunos puntos sensibles de todo el proyecto foucaultiano. Por un lado, la genealogía está elaborada desde una posición de contrapoder, en el sentido de que las descripciones de los dispositivos,

25 Dreyfus, H. L. y Rabinow, P., Michel Foucault. Beyond Structuralism and Hermeneutics (Berkeley: University of California Press, 1983).

26 Habermas, J., «Erkenntnis und Interesse», en Technik und Wissenschaft als "Ideologie» (Frankfurt am Main: Suhrkamp Verlag, 1968), 146-168.

27 Foucault se alejaría del interés hermenéutico de las ciencias humanas, para presentar todas las donaciones de sentido como estrategias de poder (Habermas da el ejemplo de la prohibición de la lucha de gladiadores bajo el influjo de un «Cristianismo humanizante», lo cual sería una tesis hermenéutica, eliminada por la genealogía, que sólo ve allí otra estrategia de poder). Cf. Habermas, El discurso filosófico de la modernidad, 302.

28 Ibíd., 295. Esto está implicado en el hecho de que Foucault considera que su descripción de la episteme moderna da cuenta de cómo pudo surgir algo así como «el hombre»en el siglo XIX, con las consecuentes «ciencias humanas» que lo tenían por objeto.

29 Es la interpretación de Paul Ricoeur, Ideología y utopía, trad. Alcira Bixio (Barcelona: Gedisa [orig. 1996], 2008); cf. Thompson, J. B., Critical Hermeneutics. A study in the thought of Paul Ricoeur and Jürgen Habermas (Cambridge: Cambridge University Press, 1981). 
las tecnologías, las disciplinas, etc., han sido realizadas habiéndose puesto, el propio Foucault, del lado de aquellos que se resisten a esas prácticas de poder. Habermas considera que esto es similar al primer Lukács, cuando atribuía al proletariado una posición particular que hacía de tal conocimiento no una «ideología», sino una clase que hablaba en nombre del «interés general». Es claro que Foucault rechazaría esta analogía con Lukács. Y es allí a donde quiere conducir Habermas: Foucault se niega a situarse explícitamente del lado de quienes resisten el poder, o del lado de aquellos que, ilusoriamente, estando siempre inmersos en las redes del poder, quieren igualmente constituir un contra-poder. Esto conduce a considerar a Foucault un "criptonormativista», que describe las prácticas discursivas desde una valoración (negativa), pero que luego no puede fundamentar esa crítica negativa, porque ha partido del supuesto de que toda fundamentación y argumentación ya es en sí otra máscara más del poder, como lo es el «humanismo» de las ciencias humanas. ${ }^{30} \mathrm{Y}$ si tuviéramos la tentación de pasar de la crítica de las ciencias humanas hacia las reflexiones sobre el biopoder y el nacimiento de la biopolítica, Habermas también allí señala el déficit normativo. Las pretensiones de validez, las justificaciones críticas del derecho, el apego a la ley y su lenguaje normativo, todo ello está inhabilitado. El poder disciplinario de la modernidad «sólo se ajusta ya a conceptos empíricos, y en todo caso no-jurídicos, de regulación y organización fácticas de formas de comportamiento y motivos de una población que por medio de la ciencia queda más o menos puesta a disposición del poder $»^{31}$.

En una sentencia que parece precursar el proyecto de Facticidad y validez, Habermas acusa a Foucault de «unilateral»:

Pero lo que da que pensar es que la teoría sólo tenga en cuenta el sistema de ejecución de penas. En cuanto pasa de la época clásica a la modernidad, Foucault ya no presta atención alguna al derecho penal y al derecho procesal penal. En caso contrario, se hubiera visto en la necesidad de someter a una detallada interpretación en términos de teoría del poder los evidentes progresos en liberalidad y seguridad jurídica, la extensión de las garantías del Estado de derecho también a ese ámbito ${ }^{32}$.

Se trata de una estrategia retórica muy propia del post-estructuralismo, al elaborar una crítica devastadora del Estado de derecho moderno y la Ilustración, estrategia que Michael Walzer ha captado casi en los mismos términos que Habermas:

30 Habermas, El discurso filosófico de la modernidad, 308.

31 Ibíd., 315. También HARDT, M. y Negri, A., que hacen biopolítica a su modo, rechazan las resistencias de un "contra-poder», cf. NEgRI, T. y HARDT, M., Empire (Cambridge, Massachusetts: Harvard University Press, 2000). Ver la crítica global de Atilio Borón, Imperio e imperialismo. Una lectura crítica de Michael Hardt y Antonio Negri (Buenos Aires: CLACSO, 2002); y en particular sobre el tema del «contra-poder», ver John Holloway, Cambiar el mundo sin tomar el poder. El significado de la revolución hoy, trad. Marcela Zangaro, 3.a ed. (Buenos Aires: Herramienta, 2005), 247 ss.

32 Habermas, El discurso filosófico de la modernidad, 316. 
Tampoco proporciona [Foucault] una genealogía del Gulag y, lo que probablemente sea más importante, su versión del archipiélago carcelario no contiene ninguna sugerencia de cómo o porqué nuestra propia sociedad no llega al Gulag. Porque tal versión requeriría aquello a lo que Foucault siempre se resiste: cierta evaluación positiva del Estado liberal ${ }^{33}$.

Finalmente, Habermas saca las conclusiones filosóficas más duras de todo el proceso de nivelación que significan la arqueología y genealogías foucaultianas: al eliminar la filosofía del sujeto, el humanismo y las ciencias humanas, que operarían únicamente en términos de relaciones sujeto-objeto, o en términos de un sujeto que se refiere a sí mismo como un «objeto más» o, en la tradición marxista occidental y fenomenológica, bajo el temor de que el sujeto se «aliene» en los objetos — siendo todo esto otras tantas estrategias de poderFoucault elimina también los problemas filosóficos que esa «filosofía del sujeto» sacó a la luz. ${ }^{34}$ Pero, ¿hay otra manera de salir de esa filosofía?.

Habermas considera que el poder en Foucault es un equivalente al concepto trascendental de "vida» en las filosofías vitalistas. El filósofo francés habría dado en el blanco al criticar el constante ir y venir entre lo empírico y lo trascendental, en las aporías de las ciencias humanas modernas, en el capítulo final de Las palabras y las cosas. Otro síntoma de lo que Foucault quiere dejar atrás, como hemos visto, es el constante imperativo de retornar a los poderes de origen (que en Heidegger y Derrida, aunque quizá se podría incluir a Husserl, están «temporalizados»). Pues bien, para el filósofo de Frankfurt todo este diagnóstico es correcto, pero da cuenta de un "paradigma agotado», es el paradigma de la filosofía del sujeto o de la conciencia, que reduce todo a relaciones sujeto-objeto, privilegiando la relación de conocimiento. Habermas propone reemplazar este paradigma por el paradigma del «entendimiento intersubjetivo», que no otorga al paradigma del sujeto o la consciencia "privilegio alguno». Los hablantes se sirven del lenguaje para diferenciarse; en cada acto de habla se despliegan contrafácticamente las pretensiones de validez que apuntan a una «comunidad ideal de habla» en la que todo se resolvería por la «coacción sin coacciones» del mejor argumento. La acción teleológica de sujetos productores (Marx) es reemplazada por los actos de habla o la "acción comunicativa», que sucede cada vez que un hablante entra, en el discurso, a interrelacionarse con un interlocutor, con el claro y lúcido objetivo de llegar a un acuerdo, un consenso, a entenderse entre sí. Aquí no habría actitud objetivante, porque lo primordial es la actitud de entendimiento entre los hablantes. No hay cosificación, porque la cosificación está implicada en un uso del lenguaje reducido a constatación de hechos; la "acción comunicativa», en cambio, implica el involucramiento del hablante para darse a entender (realiza un «acto de habla», se

33 Walzer, M., «La política de Michel Foucault», en Foucault, ed. David Couzens Hoy, trad. Antonio Bonano (Buenos Aires: Nueva Visión, 1988), 73.

34 Habermas, El discurso filosófico de la modernidad, 318. 
introduce en una «situación de habla»). ${ }^{35}$ Habermas sintetiza estos presupuestos, las «pretensiones de validez», en la Teoría de la acción comunicativa:

El acuerdo alcanzado intersubjetivamente se mide justo por estas tres pretensiones de validez susceptibles de crítica, ya que los actores, al entenderse entre ellos sobre algo y darse así a entender a sí mismos, no pueden menos que insertar sus actos de habla precisamente en esta tres relaciones con el mundo y reclamar para ellos validez bajo cada uno de estos aspectos. Quien rechaza la oferta hecha con un acto de habla que ha entendido, cuestiona por lo menos una de estas pretensiones de validez ${ }^{36}$.

Y aquí está el ejemplo de qué pretensiones se cuestionan en cada caso:

Cuando el hablante rechaza un acto de habla por no considerarlo normativamente correcto, por considerarlo no verdadero, o por considerarlo no veraz, lo que está expresando con su «no» es que la emisión no cumple las funciones de asegurar la relación interpersonal, de servir a la exposición de un estado de cosas, o de manifestar vivencias subjetivas, y por ello no estar en concordancia, bien sea con nuestro mundo de relaciones interpersonales legítimamente ordenadas, o con el mundo de estado de cosas existente, o con el mundo subjetivo de vivencias propio de cada uno $^{37}$.

Vemos así que cada pretensión de validez, que puede estudiarse en el medio bien accesible que son los actos de habla, apunta a un ámbito o «mundo»: el mundo social (que sería el conjunto de relaciones interpersonales legítimamente reguladas), el «mundo objetivo» (que sería el conjunto de lo que es o podría ser), o el «mundo propio y subjetivo». De este modo, los actos de habla remiten a ámbitos que otrora estaban circunscriptos a la "filosofía de la conciencia», y que ahora son accesibles en el ámbito de la intersubjetividad ${ }^{38}$.

Habermas también pretende superar la aporía entre lo trascendental y lo empírico (en donde lo empírico estaría reducido a relaciones de dominación). El problema de lo trascendental, que antes era jurisdicción de la filosofía de la conciencia, pasa ahora a «otra jurisdicción», el de otras ciencias, que Habermas denomina "ciencias reconstructivas», y cuyo paradigma es el estructuralismo

35 Habermas, J., Teoría de la acción comunicativa: complementos a estudios previos (Madrid: Cátedra, 1989), 482.

36 Habermas, J., Teoría de la acción comunicativa, I. Racionalidad de la acción y racionalización social, trad. Manuel Jiménez Redondo, 4.a ed. (México: Taurus [orig. 1981], 2002), 394. También aclara Habermas, ante la crítica de Agnes Heller, que «no podemos evitar tomar partido por la implantación de la racionalidad comunicativa, que siempre es inmanente al entendimiento lingüístico», Jürgen Habermas, «Réplica a objeciones (1980)», en HaBermas, J. en Teoría de la acción comunicativa: complementos a estudios previos, (Madrid: Cátedra, 1989), 409. Estas réplicas son traducción de Jürgen Habermas, "A Reply to my Critics», en Habermas - Critical Debates, ed. Thompson, J-B. y Held, D. (London: Macmillan, 1982), 219283.

37 Habermas, Teoría de la acción comunicativa I, 394.

38 Las nomenclaturas de estos «mundos» corresponden a Jürgen Habermas, "Ciencias sociales reconstructivas vs. comprensivas (verstehende) [1980]», en Conciencia moral y acción comunicativa, trad. Ramón García Cotarelo (Buenos Aires: Planeta - Agostini, 1994), 37. 
genético de Piaget. Estas ciencias van reconstruyendo los presupuestos de los hablantes, presupuestos que tienen que ver con el "saber de reglas», en situación de habla ${ }^{39}$.

No puedo seguir exponiendo la teoría de Habermas. Lo que quise mostrar es que si el proyecto de Foucault consiste en disolver el humanismo y la filosofía del sujeto (o filosofía de la conciencia) a través de una genealogía accesible en el nivel de archivo, Habermas representa un proyecto de disolución del humanismo a través de una "teoría crítica» cuyo ámbito de análisis serían los actos de habla ${ }^{40}$.

Finalmente, los desafíos del déficit normativo y la disolución del sujeto bajo la estructura, Habermas los pretende superar con la «trascendencia desde adentro», que no podemos desarrollar aquí por estrictas cuestiones de espa$\mathrm{cio}^{41}$.

\section{CRÍTICA}

Foucault y Habermas parecen acordar en varios puntos. Ambos representan la inviabilidad de un retorno a la «antropología filosófica» en sentido estricto; rechazan el humanismo como un «esencialismo» que utiliza esa supuesta esencia humana como un mecanismo de dominación social; ambos manifiestan la

39 Ibid., 43-55.

40 Sobre Habermas, Foucault y la Escuela de Frankfurt, ver HABER, «Foucault y Habermas: dos comienzos...» (ya citado) en donde se comparan dos obras clave de principios de los '60: Michel Foucault, Folie et déraison. Histoire de la folie à l'âge classique (Paris: Libraire Plon, 1961); Jürgen Habermas, Strukturwandel der Öffentlichkeit. Untersuchungen zu einer Kategorie der bürgerlichen Gesselschaft (Frankfurt am Main: Suhrkamp Verlag, 1962). Para otras consideraciones sobre la relación de estos autores con la Escuela de Frankfurt, ver David Couzens Hoy, «Poder, represión y progreso: Foucault, Lukes y la Escuela de Frankfurt», en Foucault, ed. David Couzens Hoy, trad. Antonio Bonano (Buenos Aires: Nueva Visión, 1988), 139-166; Olivier Voirol, «Crítica genealógica y crítica normativa», en Habermas / Foucault. Trayectorias cruzadas, confrontaciones críticas, ed. Ives Cusset y Stéphane Haber, trad. Heber Cardoso (Buenos Aires: Nueva Visión, 2007), 127-148.

41 «En la acción comunicativa nos orientamos por pretensiones de validez que sólo podemos entablar de hecho en el contexto de nuestra lengua, de nuestra forma de vida, mientras que a la vez la resolubilidad o desempeñabilidad de estas pretensiones, que implícitamente estamos suponiendo, apunta más allá de la provincialidad de cualquier contexto histórico dado. Quien se sirve de una lengua orientándose a entendimiento se expone a una trascendencia que opera, por así decir, desde adentro. De esta trascendencia no puede disponer el hablante, al igual que tampoco la intencionalidad de la palabra hablada (esto es, la intencionalidad con que el hablante dice lo que dice) le convierte en señor de la estructura del lenguaje. La intersubjetividad lingüística trasciende a los sujetos, pero sin convertirlos en siervos.», Jürgen Habermas, Israel o Atenas. Ensayos sobre religión, teología y racionalidad, trad. varios (Madrid: Trotta, 2001), 137-138; también publicado en Jürgen Habermas, "Sobre la frase de Horkheimer: "es inútil pretender salvar un sentido incondicionado sin Dios"» (1991), en Textos y contextos, trad. Manuel Jiménez Redondo (Barcelona: Ariel, 1996), 146-147. 
necesidad de «salir del paradigma del sujeto» en cuanto al primado de las relaciones de objetivación y de conocimiento (sujeto-objeto); ambos quieren abandonar las concepciones metafísicas del sujeto (sexualmente indiferenciado, sin tradiciones culturales, sin incidencias geopolíticas, con la «transparencia» de una presunta eliminación del otro, etc.). Esto implica transformaciones que la filosofía social crítica debe asumir. Para Foucault, la salida del paradigma humanista implica un cambio metodológico que confluye en la biopolítica, como estudio crítico de la gubernamentalidad del presente, que incluye críticas al neoliberalismo y la sexualidad, como nuevas estrategias del poder que, bajo la presunción de estar liberándonos, siguen generando redes de poder de las cuales es imposible (e ingenuo) pretender salir. Está claro que la biopolítica es un paradigma alternativo a la filosofía del sujeto, que aún está dando buenos resultados en el pensamiento contemporáneo ${ }^{42}$. Sin embargo, el déficit normativo de las investigaciones de Foucault implica que cada vez tendríamos una mejor descripción de las redes del poder, pero seríamos incapaces de comprender qué quiere decir tener "éxito» en resistir o transformar esas redes ${ }^{43}$. Esta situación, por supuesto, está implicada no sólo en el abandono de las teorías de la alienación humana (humanismo), sino en el rol que el filósofo o el intelectual deben tener en relación con las prácticas sociales de resistencia y las luchas emancipatorias (que conectan con la tradición iluminista) ${ }^{44}$.

El filósofo de Frankfurt coincide en varios puntos con Foucault, como hemos visto, lo cual se sintetiza en su tesis del agotamiento del paradigma de la filosofía del sujeto. Es en este contexto en el que Habermas, en lugar de derivar a una biopolítica (genealógica), opta por incorporar el "giro lingüístico» en la filosofía social crítica (junto a Apel), para eliminar los residuos metafísicos que todavía existían en las filosofías emancipatorias de la primera generación de la Escuela de Frankfurt (que implicaban cierta esencia humana a realizar,

42 Por ejemplo, la crítica de Agamben a la «teología política» de Schmitt, cf. Agamben, G., El reino y la gloria. Una genealogía teológica de la economía del gobierno (Homo sacer II, 2), trad. Flavia Costa y Edgardo Castro (Buenos Aires: Adriana Hidalgo editora, 2008); Espósito, R., Bios, Biopolítica y filosofía (Buenos Aires: Amorrortu, 2006).

43 Incluso se ha especulado con una teoría de la «mano invisible», análoga al liberalismo económico, en lo que también confluiría la teoría de las «redes del poder» de Foucault, cf. Couzens Hoy, D., «Introducción», en Couzens Hoy, D. (ed.) Foucault, trad. Antonio Bonano (Buenos Aires: Nueva Visión, 1988), 19.

44 No hemos tenido espacio de tratar el tema del Iluminismo, el cual fue centro de un debate que no pudo realizarse completamente entre ambos pensadores; la tesis de Habermas está en El discurso filosófico de la modernidad y en HABERMAS, J., "La modernidad: un proyecto inacabado», en Ensayos Políticos, trad. Ramón García Cotarelo (Barcelona: Península, 2000), 265-283.; el «retorno» de Foucault a «cierto tipo de Iluminismo» está en sus dos ensayos, contenidos en Foucault, M., ¿Qué es la Ilustración?, trad. Silvio Mattoni (Madrid: Las ediciones de la Piqueta, 1996). De la abundante bibliografía, debe señalarse Hubert L. Dreyfus y Paul Rabinow, «¿Qué es la madurez? Habermas y Foucault acerca de "Qué es el Iluminismo" ", en Couzens Hoy, D., Foucault, trad. Antonio Bonano (Buenos Aires: Nueva Visión, 1988), 125-138. 
a partir de la «toma de consciencia», instruida por la filosofía social crítica) ${ }^{45}$. Frente a la carga de irracionalismo que la genealogía neonietzscheana tiene a ojos de Habermas, la racionalidad y la ética implicada en los «actos de habla» ofrecen una salida «racional», «argumentativa», a la crisis de paradigma. La tarea de la filosofía se transforma profundamente; para Habermas, el filósofo ya no debería tener una función de "acomodador» de las ciencias (una forma de «fundacionalismo»), sino meramente de «vigilante» de la racionalidad de las prácticas comunicativas en el ámbito intelectual. De este modo, el filósofo se va transformando en «intelectual» ${ }^{46}$.

Tanto Foucault como Habermas coinciden en abandonar el rol del filósofo como el representante de un saber que sería la clave para la liberación humana, la emancipación de las clases oprimidas, o la realización de la esencia humana en la historia, por implicar actitudes "paternalistas» (propias del humanismo). Stéphane Haber sostiene la tesis de que los movimientos sociales de emancipación de la década de 1970 (feminismo, negritud, etc.) son los principales referentes tanto de Foucault como de Habermas, en tanto que manifestaciones a los que el intelectual puede adherir, acompañar, pero no en calidad de "vanguardia» ${ }^{47}$. A este respecto, cita el proyecto de investigación de Foucault sobre la situación de los presos en las cárceles (década de 1970), y algunas secciones de la Teoría de la acción comunicativa, en donde Habermas guardaría una relación análoga con los «movimientos sociales». Se trataría de acompañar, como intelectuales, a aquellos que están tomando la palabra, o ayudar a que puedan tomarla. Pero veamos algunas críticas.

Para Perry Anderson, jugando con el lenguaje foucaultiano, el pasaje de la episteme marxista a la posestructuralista no es de total discontinuidad. Hay un problema común: «la naturaleza de las relaciones entre la estructura y el sujeto en la sociedad y la historia humanas». El estructuralismo y el post-estructuralismo no superan ni resuelven realmente los problemas con los que se enfrentaron, sino que pretenden hacerlos superfluos, abriendo otras dimensiones de análisis ${ }^{48}$.

Habermas podría implicar cierto retorno al «humanismo», el «humanismo de la acción comunicativa», ya que es ella la que nos constituye en humanos,

45 Estas críticas al «humanismo marxista» y su «filosofía de la consciencia» están en varios lugares, por ejemplo, HABERMAS, «Réplica a objeciones (1980)», 400-412; HABERMAS, J., El discurso filosófico de la modernidad [ed. Taurus], trad. Manuel Jiménez Redondo (Buenos Aires: Taurus [orig. 1985], 1989), 99-108 (excursus).

46 Cf. Habermas, J, «La filosofía como vigilante (Platzhalter) e intérprete (1981)», en Conciencia moral y acción comunicativa, trad. Ramón García Cotarelo (Buenos Aires: Planeta - Agostini, 1994), 11-30.

47 Haber, S., "Ciencias humanas y saber emancipador en Foucault y Habermas», en Cusset, I.; Haber, S. (eds.) Habermas / Foucault. Trayectorias cruzadas, confrontaciones críticas, trad. Heber Cardoso (Buenos Aires: Nueva Visión, 2007), 201-232.

48 Anderson, P., Tras las huellas del materialismo histórico, trad. Eduardo Terrén (México: Siglo XXI [orig. 1986], 2004), 36. 
por encima de la producción ${ }^{49}$. Sin embargo, a juicio de Anderson (quien considera «muy cercano» a Habermas de los post-estructuralistas), el grave problema es la elevación del paradigma comunicativo o del lenguaje (lo cual coincide parcialmente con las críticas del propio Dussel a Apel y Habermas, quien acepta la validez del "giro lingüístico» y los «actos de habla» como "grito» de las víctimas desde la vulnerabilidad de sus cuerpos, su «carne» [heb. basar] $)^{50}$.

El primer responsable es, naturalmente, Lévi-Strauss (otro gran crítico del «humanismo»). Su hallazgo consistió en aplicar el modelo lingüístico para comprender la estructura de las relaciones de parentesco y la sociedad. Sin embargo, a ojos de Anderson, se trata de una «victoria pírrica» sobre el marxismo y el paradigma de la «producción». Dice Anderson:

El parentesco no puede compararse con el lenguaje como sistema de comunicación simbólica en el que se «intercambian», como diría Lévi-Strauss, respectivamente mujeres y palabras, desde el momento en que ningún hablante enajena el vocabulario a un interlocutor, sino que puede reutilizar libremente cada palabra «dada» tantas veces como desee [mientras que no sucede eso con las «mujeres» que entregan los padres en casamiento]. El término intercambio autoriza menos todavía una elisión de la economía: aunque a los hablantes y a las familias de la mayoría de las sociedades pueda atribuírseles al menos una equivalencia aproximada de palabras y mujeres, es evidente que no ocurre lo mismo con sus bienes. En otras palabras, ninguna economía puede ser definida en una primera instancia en términos de intercambio: la propiedad y la producción son siempre previas ${ }^{51}$.

Por otra parte, en el paradigma lingüístico no hay subjetividades colectivas, porque si todos hablamos a la vez, nadie puede entenderse. La relación entre estructura (lengua) y sujeto apunta a individuos, que para Habermas serían «individuos que quieren diferenciarse ${ }^{52}$ (entendiendo la modernidad como «proceso de diferenciación»). Según Anderson, la gran falla de esta trasposición del paradigma de la producción al paradigma del lenguaje consiste en la imposibilidad de concebir sujetos colectivos:

Naciones, clases, castas, grupos, generaciones. Precisamente por eso, la acción de estos sujetos es capaz de producir transformaciones profundas en esas estructuras. Esta distinción fundamental es una barrera insuperable

$49 \quad$ Ibid., 73.

50 Cf. Dussel, E, Ética de la Liberación en la edad de la globalización y de la exclusión (Madrid: Trotta, 1998); Apel, K-O. y Dussel, E., Ética del discurso y ética de la Liberación (Madrid: Trotta, 2004); Enrique Dussel, La ética de la Liberación ante el desafío de Apel, Taylor y Vattimo, con respuesta crítica inédita de K. O. Apel (México: Universidad Autónoma de México, 1998); Enrique Dussel, ed., Debates en torno a la ética del discurso de Apel. Diálogo filosófico NorteSur desde América Latina (México: Siglo xxI, 1994).

51 ANDERson, P., Tras las huellas del materialismo histórico, 48.

52 Cf. Habermas, J, «Inclusión: ¿incorporación o integración? Sobre la relación entre nación, Estado de derecho y democracia (1996)», en La inclusión del otro. Estudios de teoría política (Barcelona: Paidós, 1999), 107-136. 
para cualquier transposición de modelos lingüísticos a procesos históricos de tipo más amplio ${ }^{53}$.

En el caso de Habermas, las críticas de Anderson tienen que ver con una «concepción angélica del lenguaje», que se opondría a la versión «demoníaca» de los post-estructuralistas.

Me serviré de varias críticas que se le han realizado a Habermas, con las cuales concuerdo. John Sitton critica a Habermas el dualismo que establece entre sistema y mundo de la vida (Lebenswelt). La Lebenswelt constituye los saberes y las prácticas sedimentadas en la sociedad, de manera espontánea, a las que el Sistema va "colonizando" con los procesos de racionalización. El «sistema» representa las estructuras de administración y control que se van independizando del mundo de la vida (economía y administración pública), pero que para ser «legítimas», deben estar ancladas en ella. En las sociedades del "capitalismo tardío», el Estado de Bienestar hunde sus raíces en los procesos modernos de racionalización de la Lebenswelt. La reproducción material de la Lebenswelt se realiza por sistemas autónomos, pero la reproducción simbólica se realiza por la acción comunicativa de individuos que buscan entenderse. Sitton objeta a Habermas el dualismo y la (falsa) noción de autonomía que otorga al sistema capitalista en su auto-reproducción ${ }^{54}$. Habermas subestimaría la amplia zona de conflictos que emergen o están por emerger en las sociedades contemporáneas, y representa así un grave retroceso (y no un avance) en la consideración de los problemas de las sociedades contemporáneas desde una perspectiva socialista.

La distinción que hace Habermas entre el mundo de la vida y el sistema obstruye nuestra habilidad para comprender lo que implica que el capitalismo sea una construcción política. A su vez, esta debilidad está íntimamente ligada con la incertidumbre del papel que representan las clases en la teoría social de Habermas ${ }^{55}$.

Según Sitton, el abandono de la centralidad de los conflictos entre clases sociales, para ser reemplazado por la teoría de sistemas (autonomía de los sistemas), implica una «naturalización» del capitalismo. Una crítica similar es la que realiza Alex Callinicos, quien acusa a Habermas, no sólo de «naturalizar el capitalismo", sino de describir la Lebenswelt en un sentido "aproblemático», en el cual ya se ha diluido completamente la «crítica de la ideología». En sus juicios más duros, Callinicos llega a decir que Habermas «naturaliza la explotación ${ }^{56}$.

53 Anderson,P., Tras las huellas del materialismo histórico, 51.

54 Cf. Sitton, J, Habermas y la sociedad contemporánea, trad. Juan Carlos Rodríguez Aguilar (México: Fondo de Cultura Económica, 2006), 240.

55 Ibid., 297.

56 Callinicos, A., The Resources of Critique (Cambridge: Polity Press, 2006), 32-34. Ver también Axel Callinicos, Contra el posmodernismo, trad. Magdalena Holguín (Buenos Aires: RyR, 2011). 
Finalmente, Castoriadis ha señalado ciertas ingenuidades del planteo habermasiano en cuanto a la centralidad del «mercado» ${ }^{57}$, y ha intentado mostrar que las teorías marxistas de la revolución (con su consiguiente «humanismo») fueron expresión de un movimiento mayor: el movimiento obrero ${ }^{58}$. Sin embargo, Castoriadis es ambiguo en cuanto al rol de los nuevos movimientos sociales y cuáles serían las razones para motivar una profunda transformación social, más allá de la (fallida) revolución marxista. Castoriadis presenta la razón de esto en una sentencia que me sirve para cerrar este escrito:

No creo que los hombres se movilicen alguna vez para transformar la sociedad — sobre todo en las condiciones del capitalismo moderno-, y para establecer una sociedad autónoma. Querrán verdaderamente y efectivamente la autonomía cuando ella se manifieste como la portadora, la condición, casi como el acompañamiento - pero indispensable- de algo sustantivo que quieren realizar de verdad, que tendrá para ellos valor, y que no logran hacer en el mundo actual. Pero esto querrá decir que hará falta que emerjan nuevos valores en la vida histórico-social ${ }^{59}$.

Instituto Universitario ISEDET

Buenos Aires, Argentina

droldan1976@gmail.com

DAVID A. RoldÁN

[Artículo aprobado para publicación en noviembre de 2013]

57 CAstoriadis, C., Una sociedad a la deriva. Entrevistas y debates (1974-1997), trad. Sandra Garzonio (Buenos Aires: Katz Editores, 2006), 117.

58 Ibíd., 112.

$59 \quad$ Ibid., 99. 